actual de las religiones vacía igualmente de contenido la idea de un fundamento religioso de lo social. $Y$ sin embargo el fenómeno de la secularización no conduce a una anemia de la referencia religiosa, aun cuando debilite la presencia visible de las Iglesias. Más bien desplaza el papel de la trascendencia, que debe entenderse no tanto como base firme de la sociedad - como objeto poseído por una institución religiosa, sino como espacio vacío que invita al compromiso de libertades responsables animadas por un espíritu vivo. El error de las visiones radicales de la secularización conduce a considerar como vana toda trascendencia, buscando incluso la incorporación de verdaderos sustitutivos. Estas visiones ignoran que la sociedad moderna, por su misma constitución interna, no puede privarse de una forma de trascendencia, fuera de la cual una tal sociedad perdería su vitalidad y su dinamismo. En el fondo, la experiencia de esta trascendencia se realiza en el corazón del debate democrático hecho de confrontaciones: el imperativo político de escuchar y de tomar en serio las corrientes de pensamiento y las expectativas sociales para tratarlas políticamente abre un debate sin final previsible. Aceptar un intercambio de este tipo, sin anticipar su final ni querer cerrarlo demasiado aprisa, pone nuestras sociedades ante exigencias a la vez políticas, morales y profundamente espirituales. Es en el seno de esta comu-

\section{Derecho mercantil}

EnRIQUES, Luca (a cura di) - KRAAKMAN, Reinier R., Davies, Paul, Hansmann, Henry, Hertig, Gérard, Hopt, Klaus J., KandA, Hideki y Rock, Edward B. (2006) Diritto societario comparato. Un approccio funzio- nicación generalizada donde se puede experimentar una trascendencia en relación con los intereses privados y una apertura que lleve a la sociedad a una mejor toma de conciencia de la alteridad en todas sus formas (págs. 290-291).

Después de la lectura de estas páginas uno tiene que agradecer a su autor la originalidad de su pensamiento y el rigor para exponerlo desde un profundo conocimiento de la tradición filosófica y teológica. No aboga por una vuelta al pasado, que elimine todos los males de la modernidad. Pero se esfuerza por extraer las lecciones de esta historia y buscar creativamente nuevas vías de articulación entre lo religioso y lo político, más allá de los maximalismos de la absoluta separación o de la nostalgia de una identificación ya inaceptable para casi todos. En esta búsqueda juega un papel relevante su conciencia de eso que llama "la anormalidad cristiana": la capacidad del cristianismo, desde su prehistoria veterotestamentaria, para servir de base a una nueva forma de entender estas relaciones. Y esta revisión interesa no sólo al cristianismo: también a la política que ha de vivirse ya, no desde la ignorancia de la religión, sino desde la conciencia de su permanencia, incluso buscando en lo teológico elementos para recuperar algo de su legitimidad hoy tan en crisis. [Ildefonso CAMACHO LARAÑA]

nale, Bologna (Oxford 2004), II Mulino (Manuali-Diritto), 290 pp.

La obra original data de 2004 y es el resultado de una larga colaboración de 
los siete autores, procedentes de cinco países, a partir de una idea inicial gestada nueve años atrás. En la introducción se describe la orientación de la obra, con cuatro adjetivos: internacional, funcional, neutral y breve. Es internacional por la propia extracción de los autores, por su nivel de abstracción y por la toma como referencia legislativa de los ordenamientos de cinco países (Francia, Alemania, Japón, Reino Unido y Estados Unidos).

La apelación a la funcionalidad es el carácter más enfatizado, y más polémico. Así lo reconocen los mismos autores cuando aluden a las críticas con que se ha recibido en Europa la corriente exegética del análisis económico del Derecho. Más que un rechazo a esta tesis ha existido, a nuestro entender, una reacción previsible al intento de una imposición -totalizadora- de esta línea hermenéutica, por parte de juristas seducidos por las últimas modas foráneas, especialmente, las estadounidenses. No obstante estos debates, los autores subrayan con reiteración que la obra indaga en la base económica del Derecho de sociedades.

En relación con la anterior característica -y en clara contradicción, si somos rigurosos-, la obra tiene, a decir de los autores, una orientación neutral en cuanto no tiene por objeto realizar juicios de valor sobre los distintos ordenamientos jurídicos (aunque se hacen, en forma implícita en la mayoría de las ocasiones), ni realizar propuestas de reforma. Los autores han querido huir, en forma premeditada y proyectada, de esta tentación. Por último, el libro tiene unas dimensiones reducidas, pues no es una exposición detallada del Derecho de sociedades en distintos Estados, sino una descripción que llama la atención sobre el importante grado de convergencia mundial existente en el régimen de la sociedad de capital abierta y una validación del método funcional que preside la obra.

El capítulo primero tiene un título rotundo, casi provocador: ¿Qué es el derecho societario? Se afirma que, frente a quienes destacan las diferencias entre distintos ordenamientos, los autores coinciden en que existe una sustancial uniformidad en el tipo social de la sociedad de capital abierta. Esta uniformidad se apoya en cinco características jurídicas fundamentales: la personalidad jurídica de la sociedad, la responsabilidad limitada de los socios por las deudas sociales, la transmisión de las acciones, la existencia de un órgano de administración encargado de la gestión y representación social y los inversores que ostentan la propiedad de la sociedad. Se advierte, como era necesario desde un principio, que estas características están extraídas de las sociedades anónimas abiertas titulares de las grandes empresas. Los autores adelantan que estos rasgos facilitan la integración del Derecho de sociedades a escala mundial, en coherencia con la dimensión de los mercados en los últimos años. Este capítulo primero termina con una nueva cuestión de fondo: ¿Cuál es el fin del Derecho de sociedades? Los autores no acogen una concepción radical-contractualista del contrato de sociedad, que remitiría el fin de la sociedad al fin de los socios de control. Por el contrario, sorprenden al lector con una tesis -de desarrollo abierto, en algunos extremos- cercana a las teorizaciones sobre la función social de la empresa. Afirman que la función propia del Derecho de sociedades es aumentar o maximizar el bienestar social agregado o conjunto 
de todos los stakeholders de la sociedad (accionistas, trabajadores, suministradores y clientes) sin imponer sacrificios indebidos $y$, además, si es posible procurar beneficios a terceros como la comunidad local o el medio ambiente.

El capítulo segundo lleva por título Los problemas de "agency" y las estrategias normativas. Parte de la afirmación de que el Derecho de sociedades desarrolla dos funciones principales: establece la estructura de las sociedades de capital y trata de contener los conflictos de intereses entre los diversos stakeholders. Estos conflictos presentan las características que los economistas definen como problemas de agencyo problemas del principal-agente, esto es, cuando el beneficio del principal depende de la actuación del agente, que debe actuar en interés del principal antes que en su propio interés. Estamos ante una construcción del Derecho de sociedades $y$, en general, del Derecho patrimonial grata a la línea interpretativa representada por el análisis económico del Derecho. Esta exégesis sitúa como eje de la interpretación, aplicación e integración del Derecho (empezando por el Derecho privado patrimonial) el elemento de la eficiencia económica. En la obra recensionada, la adhesión a estos parámetros interpretativos está enriquecida por la importancia atribuida a los intereses supraindividuales.

Los autores, en una interpretación amplia de la teoría de la agency, distinguen tres problemas de agency en Derecho de sociedades. Primero, el conflicto entre los propietarios de la empresa (principal) y los administradores (agente). Segundo, el conflicto entre los socios de control (agente) y los socios minoritarios o inver- sores (principal). Tercero, el conflicto entre la sociedad y los socios (agente) y los terceros con los que contrata como, por ejemplo, los acreedores, los trabajadores y los consumidores (principal). El Derecho puede jugar un papel importante en la reducción de los costes de agency o de transacción, lo que resulta interesante para todas las partes, tanto el principal como el agente.

El capítulo tercero, bajo el título El gobierno de la sociedad de capitales, aplica los tres problemas de agencyidentificados al órgano de administración y al gobierno de la sociedad. Son de interés las alusiones a las reglas de buen gobierno corporativo, entre las que destacan las recomendaciones siguientes: órganos de administración colegiados con pocos miembros, existencia de comités específicos sobre información financiera, retribuciones y nombramientos, frecuentes reuniones y preferencia por una mayoría de administradores independientes. Los autores comentan que los Estados Unidos son el lugar de nacimiento del movimiento del gobierno corporativo, y que su desarrollo ha ido de la mano de recientes oleadas de escándalos financieros a partir de la década de los ochenta del pasado siglo.

A modo de reflexión final sobre los conflictos entre los socios de control y los administradores ejecutivos se apunta que estos conflictos son más acusados en Estados Unidos debido a la dispersión accionarial. En Francia y en Reino Unido, en este caso con la ayuda de los inversores institucionales, los socios de control determinan la política de la sociedad. En Japón, las participaciones accionariales cruzadas y los acuerdos entre sociedades, provocan la prevalencia 
de los administradores ejecutivos ( $y$, en su caso, de los ejecutivos no administradores). En Alemania, la dirección corresponde a los socios de control, si bien está atemperada por la presencia de los trabajadores en los órganos de administración. Los autores adelantan la idea de que en los periodos de prosperidad y crecimiento económico se intensifica el poder de los ejecutivos en los gobiernos corporativos y, a la inversa, en las etapas de recesión y crisis económica se fortalece el control de los socios y los movimientos de reforma del gobierno corporativo.

Como reflexión general a los conflictos entre los socios de control y los socios inversores o minoritarios, se apunta que la protección de los socios minoritarios es inversamente proporcional al poder de los socios en su conjunto. Se afirma que sólo en los Estados Unidos, con una estructura accionarial dispersa, se tutela de manera efectiva a los socios minoritarios a través de los administradores independientes, los derechos de los socios y los deberes de los administradores. Aunque cabe la duda de si esta defensa no deriva, directamente, de la estructura accionarial dispersa. Se destaca que, en las últimas décadas, todos los ordenamientos societarios son favorables a reglas de gobierno societario que tutelen a los socios minoritarios.

La tutela de los terceros con los que la sociedad contrata (por ejemplo, trabajadores, suministradores o consumidores) es la menos desarrollada. El experimento más interesante en el gobierno corporativo tras la Segunda Guerra Mundial fue la admisión, en numerosos países europeos, de la participación de los trabajadores en los órganos de administración de las grandes sociedades. El ejemplo más destacado y perfeccionado es la experiencia alemana, que se interpreta como un sistema sustitutivo del continuo control estatal y conduce a un aumento del poder de los administradores ejecutivos (y de los ejecutivos no administradores).

El capítulo cuarto está dedicado a la tutela de los acreedores, materia de interés acrecentado, en unas sociedades, como las de capital abiertas, que atribuyen la responsabilidad limitada a los socios por las deudas sociales. En esta tutela del crédito, el recurso a las normas legales es común a la Europa continental, mientras en Estados Unidos faltan muchas de estas normas (por ejemplo, el capital social mínimo o el régimen de los grupos de sociedades), lo que se suple con el recurso a conceptos jurídicos indeterminados o cláusulas generales (por ejemplo, el levantamiento del velo de la personalidad jurídica). La justificación de esta distinta orientación es, a juicio de los autores, doble: por un lado, engarza con las diferencias entre los ordenamientos latinos y germánicos o del civil law y los ordenamientos anglosajones o del common law; y, por otro lado, está ligada al diverso funcionamiento de los mercados de capitales, más conservadores y concentrados en la banca en el Continente europeo. En alternativas como ésta, los autores manifiestan una preferencia por las soluciones vigentes en Estados Unidos, de ahí que planteen, abiertamente, el abandono de las normas sobre conservación del capital social dado, y la justificación es reveladora, que su tutela es muy costosa. Lo que no les impide glosar que la protección apoyada en cláusulas generales (por ejemplo, para ordenar la responsabilidad de los administradores por daños al patrimonio social o la 
responsabilidad de los auditores) en la práctica no ha venido funcionando-hasta los escándalos financieros de principios de siglo- en Estados Unidos.

El capítulo quinto constituye una panorámica sobre problemas de creciente interés en todos los ordenamientos societarios: el régimen de las operaciones entre partes (por ejemplo, los administradores o los socios de control) en conflicto de intereses con la sociedad. En la actualidad, razones de índole práctica determinan que todos los ordenamientos admitan estas operaciones. Aunque, con la misma tónica general, son objeto de diversas medidas de control operaciones como la contratación entre los administradores y la sociedad, la determinación de la retribución de los administradores y el aprovechamiento por los administradores de oportunidades de negocio de la sociedad.

El capítulo sexto, dedicado a las operaciones extraordinarias, aplica a estas decisiones societarias el esquema general de la obra de un planteamiento de casos; el análisis de las estrategias de regulación -vía normas legales, vía cláusulas generales- de los distintos ordenamientos analizados distinguiendo las relaciones entre administradores y socios de control, entre éstos y socios minoritarios o inversores, y entre administradores y socios de controly terceros, en este caso, acreedores y trabajadores; $y$ unas reflexiones o conclusiones que recapitulan las grandes orientaciones identificadas. En la identificación de los casos se barajan tres elementos para delinear las operaciones extraordinarias en Derecho de sociedades: se trata de operaciones de gran valor atendiendo a las dimensiones del patrimonio social, estamos ante decisiones de escasa com- plejidad desde la perspectiva de la gestión empresarial de modo que pueden ser adoptadas por los socios y las decisiones en cuestión pueden generar, al menos en potencia, un conflicto con los intereses de los administradores. Por ejemplo, se apunta que los administradores que negocian una cesión del control de la sociedad se encuentran en una situación de periodo final (end game) que determina que las decisiones que adopten, sean en uno $u$ otro sentido, tienen con contraparte a los nuevos propietarios. Con estos elementos se pasa revista, con brevedad, a acuerdos sociales como los de fusión y escisión, la modificación de los estatutos sociales, la cesión de la actividad o del patrimonio social, el aumento o la reducción del capital social, la emisión de nuevas acciones, la adquisición de las acciones propias, la distribución de dividendos y la solicitud de concurso.

El capítulo séptimo aborda una materia amplísima, como es la de la adquisición del control en las sociedades abiertas. La magnitud del contenido sólo permite una descripción de problemas usuales en las tomas de control, y el habitual análisis de conflictos de intereses (agency) se limita a subrayar la aparición de un nuevo sujeto, el adquirente, y la posición dual, entre la sociedad oferente y la que gestionan, en la que se sitúan los administradores de la sociedad absorbida.

El capítulo octavo, y último, analiza la protección de los inversores en los mercados de valores cuando las sociedades abiertas emiten valores negociables, especialmente, nuevas acciones. La normativa de referencia, como resulta obligado, no es el Derecho societario sino el Derecho del mercado de valores. Los autores 
comentan las cuatro estrategias que, con distinto desarrollo y rigor, combinan los ordenamientos analizados: las obligaciones de información de las sociedades emisoras -en el momento de la emisión y durante toda la cotización- sobre su situación patrimonial, financiera y de actividad y sobre las características de los valores emitidos (es el eje del sistema tuitivo); el control de mérito o sustancial realizado por la autoridad de vigilancia del mercado de valores; la normativa sobre las condiciones de emisión de los valores y sobre el cese de cotización; y la tutela de los inversores frente a prácticas fraudulentas con apoyo en cláusulas generales como la corrección, el interés público o la diligencia exigible.

Al hilo de la exposición se realiza alguna consideración general sobre los sistemas contables anglosajones (Estados Unidos y Reino Unido) y los del Continente europeo. Estos últimos se han aproximado a los principios contables anglosajones basados en el principio de representación verdadera y correcta (true and fair view), frente al tradicional principio continental de prudencia valorativa. Las diferencias de los sistemas contables están ligadas a las distintas fuentes de financiación externa, en la tradición estadounidense y británica las sociedades abiertas recurren en mucha mayor medida a los mercados de capitales, que tienden a penalizar la opacidad en las valoraciones contables.

La obra termina con unas reflexiones conclusivas donde los autores justifican el método funcional utilizado, realizan una valoración general de los resultados obtenidos y exponen un amplio campo para futuras investigaciones. Los autores afirman que, aunque centrados en los cinco ordenamientos indicados, la obra extiende su utilidad a otros ordenamientos de su entorno. Esta apreciación es plenamente aplicable a España. Aunque a título de curiosidad cabe reseñar que el Derecho de sociedades español es citado una sola vez en nota a pie (y como Derecho histórico). Muchos de los problemas analizados en el libro han sido -y son- objeto de reciente debate doctrinal y jurisprudencial en España, y numerosas reformas legales sobre las sociedades abiertas y los mercados secundarios de valores han tenido lugar en nuestro país en los últimos veinte años. Un solo ejemplo de actualidad y calado, acaba de promulgarse una importantísima modificación de nuestro Derecho contable para su adaptación a las Normas Internacionales de Contabilidad, asumidas a inicios del segundo milenio por la Unión Europea (la Ley 16/2007, de 4 de julio).

La impresión suscitada es que, en España y en el entorno de los países desarrollados, las reformas legislativas en materias relativas al mercado y sus agentes están respondiendo, cada vez más a estímulos de convergencia internacional, y progresivamente menos a singularidades nacionales. La globalización económica no sería completa si no va seguida -o precedida- por una aproximación entre los grandes sistemas jurídicos, máxime en materias como las sociedades de capital abiertas titulares de las grandes empresas y grupos de empresas. [Manuel Paniagua ZURERA] 